\title{
Small Bowel Cleanliness in Capsule Endoscopy: A Case-control Study Using Validated Artificial Intelligence Algorithm
}

\section{Dong Jun Oh}

Dongguk University Ilsan Hospital, Dongguk University College of Medicine

\section{Youngbae Hwang}

Chungbuk National University

\section{Ji Hyung Nam}

Dongguk University Ilsan Hospital, Dongguk University College of Medicine

Yun Jeong Lim ( $\nabla$ drlimyj@gmail.com )

Dongguk University Ilsan Hospital, Dongguk University College of Medicine

\section{Research Article}

Keywords: Artificial intelligence, Bowel cleanliness, Capsule endoscopy, Colonoscopy, Purgatives

Posted Date: March 2nd, 2022

DOI: https://doi.org/10.21203/rs.3.rs-1354466/v1

License: (c) (i) This work is licensed under a Creative Commons Attribution 4.0 International License. Read Full License 


\section{Abstract}

Background: Small bowel capsule endoscopy (SBCE) may need to be performed immediately after colonoscopy without additional bowel preparation if active small bowel diseases are suspected. However, it is unclear whether the small bowel cleanliness is adequately maintained in SBCE immediately after colonoscopy.

Methods: Cases of SBCE in which polyethylene glycol were used were included retrospectively. We compared the small bowel cleanliness scores using a validated artificial intelligence (Al) algorithm (cutoff score $>3.25$ for adequate).

Results: Among 85 enrolled cases, 50 cases (58.8\%) were the study group. The mean time from last dose of purgative administration to SBCE was $6.86 \pm 0.94$ hours in study group and $3.00 \pm 0.18$ hours in control group. Seventy-five cases (88.2\%) were adequate small bowel cleanliness, which was not different between the two groups. The mean small bowel cleanliness score for study group was $3.970 \pm 0.603$, and for control group was $3.937 \pm 0.428$. In the study group, better colon preparation resulted in higher the small bowel cleanliness score $(p=0.015)$.

Conclusions: Small bowel cleanliness was also adequately maintained in SBCE immediately after colonoscopy. There was no difference between the time and volume of purgative administration and small bowel cleanliness.

\section{Introduction}

Small bowel capsule endoscopy (SBCE) is currently the key modality for the diagnosis of various small bowel diseases, such as obscure gastrointestinal (GI) bleeding, known or suspected small bowel Crohn's disease without stenosis, small bowel tumors or polyposis, and refractory celiac disease. ${ }^{1-3}$ Unlike conventional (wired) endoscopy, bowel cleansing cannot be actively performed during the SBCE examination. So proper bowel preparation before SBCE is important to improve small bowel mucosal visualization. $^{4}$

For bowel preparation before colonoscopy, the European Society of Gastrointestinal Endoscopy (ESGE) recommends split-dose preparation or same-day preparation for elective colonoscopy. ESGE also recommends that the last dose of purgative be taken within 5 hours before the colonoscopy and completed 2 hours before the colonoscopy. ${ }^{5}$ The American Society for Gastrointestinal Endoscopy (ASGE) recommends that second dose of purgative administration be started 3 to 8 hours before the endoscopy. ${ }^{6}$ However, the consensus on the timing and method of the bowel preparation for SBCE is still controversial. $^{7}$

If small bowel bleeding is suspected after upper endoscopy and colonoscopy in patients with GI bleeding, SBCE is performed. ${ }^{1-3,8}$ In this case, it is recommended to perform SBCE as soon as possible to increase the diagnostic yield of small bowel bleeding. ${ }^{4,9}$ SBCE should also be considered when non-obstructive 
small bowel Crohn's disease is suspected on colonoscopy. ${ }^{10}$ Therefore, depending upon the patient, SBCE may need to be performed immediately after colonoscopy.

However, there is a lack of research on whether small bowel cleanliness can be appropriate when SBCE is performed immediately after colonoscopy. Nevertheless, additional purgative administration or fasting for SBCE is also a burden on the patient and there is a risk of delayed diagnosis. If the small bowel cleanliness is significantly poor in SBCE immediately after colonoscopy, additional preparation may be required after colonoscopy and before SBCE. Thus, it is necessary to compare whether there is a difference in small bowel cleanliness between SBCE immediately after colonoscopy and SBCE alone.

Recently, a study using an artificial intelligence (Al) algorithm trained by PillCam (GIVEN Imaging Ltd., Yoqneam, Israel) images was conducted. This validated Al algorithm calculated an objective and automated small bowel cleanliness score for the full-length small bowel images. ${ }^{11}$ In this study, we used a validated Al algorithm and compared small bowel cleanliness score between SBCE immediately after colonoscopy and SBCE alone. So, we decided to identify whether colonoscopy before SBCE affected the difference in small bowel cleanliness scores.

\section{Results}

\section{[1] Baseline characteristics}

Out of 100 cases satisfying the inclusion criteria, 85 cases were finally enrolled. The mean age of the patients who underwent SBCE was 49.2 years, and $60 \%$ were male. The main reasons for SBCE were suspected small bowel bleeding (45.9\%) and Crohn's disease (43.5\%). SBCE immediately after colonoscopy was performed in $58.8 \%$ of the SBCE cases, and sedative colonoscopy was performed in all cases. The mean gastric transit time was $1.12 \pm 1.16$ hours, and the mean small bowel transit time was $5.64 \pm 2.35$ hours. The mean gap from the start of last dose of purgative administration to SBCE was $5.27 \pm 2.04$ hours. The mean gap in SBCE immediately after colonoscopy was $6.86 \pm 0.94$ hours, and the mean gap in SBCE alone was $3.00 \pm 0.18$ hours (Table 1).

\section{[2] Small bowel cleanliness scores calculated by the Al algorithm}

The mean number of full-length images in SBCE was 12068.8 \pm 6597.5 . The mean cleanliness score of all SBCE cases calculated by the Al algorithm was $3.956 \pm 0.535$. The mean score in the group with SBCE immediately after colonoscopy was $3.970 \pm 0.603$ and the mean score in the group with SBCE alone was $3.937 \pm 0.428$. There was no significant difference between the two groups ( $p=0.785)$ (Fig. 1$)$. Of the all SBCE cases, $88.2 \%$ showed adequate mucosal visualization (score $>3.25$ ), and $50.6 \%$ showed good mucosal visualization (score $>4.0$ ) (Table 2).

In univariate analysis, males and delayed gastric transit time were associated with inadequate cleanliness. But no statistical significance was observed in multivariate analysis. There was no statistical significance between other variables and adequate cleanliness score (Table 3). 


\section{[3] Purgative administration time and small bowel cleanliness scores}

The time from the last dose of purgative administration to SBCE was divided into 3 hours and 7 hours intervals. The mean small bowel cleanliness score in 3 hours interval was $3.937 \pm 0.428$, interval between 3 and 7 hours was $4.003 \pm 0.577$, and more than 7 hours interval was $3.933 \pm 0.641$ (Fig. 2). There was no significant difference between the three groups $(p=0.831)$.

\section{[4] Association with colon preparation scale and small bowel cleanliness scores}

In the case of performing SBCE immediately after colonoscopy, the colon preparation scale was measured by Aronchick Scale (inadequate excellent). ${ }^{12}$ Poor preparation was confirmed in 6 cases, fair preparation in 24 cases, good preparation in 14 cases, excellent preparation in 6 cases, and no inadequate preparation. The mean small bowel cleanliness score in poor preparation was $3.393 \pm 0.529$, fair preparation was $3.915 \pm 0.635$, good preparation was $4.116 \pm 0.469$, and excellent preparation was $4.421 \pm 0.374(p=0.015)$ (Fig. 3).

\section{[5] Diagnostic yield according to pre-colonoscopy and small bowel cleanliness scores}

In the case of performing SBCE immediately after colonoscopy, the diagnostic yield for small bowel bleeding was $43.5 \%, 63.6 \%$ for Crohn's disease, $50 \%$ for tumor or polyposis, $100 \%$ for drug induced enteropathy. There was no statistically significant difference when compared with SBCE alone (53.3\% for small bowel bleeding, $64.7 \%$ for Crohn's disease, $33.0 \%$ for tumor or polyposis). (Table 1 )

When the diagnostic yields were compared with the adequate and inappropriate cleansing groups, small bowel bleeding was $42.4 \%$ vs $80 \%$, Crohn's disease $65.7 \%$ and $50.0 \%$, and tumor or polyposis $50.0 \%$ vs $0.0 \%$. There was also no statistically significant difference. (Table 3 )

\section{[6] Safety of taking capsule endoscope after sedative colonoscopy}

To fully wake up from sedation, antidotes such as flumazenil and naloxone were administered, and sufficient recovery time was allowed. Also, before taking the capsule endoscope, it was confirmed that there was no problem swallowing water. No adverse events occurred when the capsule endoscope was taken after sedation colonoscopy in this study.

\section{Discussion}

In this study using a validated Al algorithm, we confirmed that small bowel cleanliness was adequately maintained in SBCE immediately after colonoscopy, similar to that in SBCE alone. Also, there was no difference between the time and volume of purgative administration and small bowel cleanliness. However, in poor colon preparation, small bowel cleanliness score was not as good as in fair, good and excellent colon preparation. So, if the colon preparation is good, SBCE can be performed immediately after colonoscopy, but, if colon preparation is not good, additional bowel preparation before SBCE may be necessary. 
In the case of SBCE immediately after colonoscopy, we expected poor bowel preparation due to air insufflation during colonoscopy and the digestive enzymes constantly secreted by the small bowel. However, there was no relationship between SBCE immediately after colonoscopy and small bowel cleanliness.

Adequate bowel cleanliness is one of the important factors for the performance and diagnostic capacity of SBCE. ${ }^{4,13}$ However, since small bowel cleanliness is subjective and takes a long time to be measured by clinicians, intra-observer variation is inevitable. ${ }^{14}$ For this reason, several studies have been conducted to objectively identify the cleanliness of SBCE using an Al algorithm. ${ }^{11,15-17}$ We were able to confirm the objective small bowel cleanliness scores by using a validated Al algorithm that was trained using SBCE images. ${ }^{11}$

Whether to take a purgative before SBCE, what type, and the ideal time to take it are still controversies. ${ }^{4,18}$ First, there is controversy about the effectiveness of purgative preparations. In a meta-analysis study comparing fasting with clear liquid intake only and purgative administration, there was no significant difference between the two preparation methods in diagnostic yield and mucosal visualization. ${ }^{19}$ Also, two randomized clinical trials (RCTs) reported that there was no difference in mucosal visualization when clear liquids and purgatives were compared. ${ }^{20,21}$ However, a recent multi-center RCT reported that taking one liter of PEG on the same day of the SBCE examination resulted in superior small bowel mucosal visualization compared to the fasting alone group ( $66.3 \%$ for one liter of PEG vs $32.5 \%$ for fasting). ${ }^{22} \mathrm{~A}$ Korean study that analyzed nationwide data found that $70 \%$ of the patients with SBCE had taken two liters of PEG and ascorbic acid since 2014. But there was no statistical significance in the comparison of adequate bowel preparation between the two liters of PEG and the fasting alone. $(68.3 \%$ for two liters of PEG vs $70.4 \%$ for fasting). ${ }^{23}$ Regarding the purgative administration time, one article mentioned that it should be taken 12 hours before SBCE. ${ }^{24}$ However, a recent multicenter study reported that low-dose PEG administration four hours before SBCE, which was similar to the protocol in our hospital, was ideal. ${ }^{22}$

Although there was no significant difference between purgative interval and small bowel cleanliness score, a significant correlation was confirmed with colon preparation scale and small bowel cleanliness score. Even in poor colon preparation, the mean small bowel cleanliness score $(3.393 \pm 0.529)$ was higher than 3.25 , which is the cut-off value of adequate cleanliness. But as the colon preparation was better, the small bowel cleanliness score was higher $(p=0.015)$. Therefore, in case of poor colon preparation, additional purgative administration before SBCE should be considered.

In terms of diagnostic yield, there was no significant difference with whether pre-colonoscopy was performed or not. However, the diagnostic yield of small bowel bleeding was slightly higher in the inadequate cleansing group than in the adequate cleansing group ( $80 \%$ vs $42.4 \%, p=0.117)$. It was determined that the Al algorithm measured the low cleanliness score in the case of active bleeding because mucosal visualization was lowered by blood. Therefore, in the case of a low small bowel cleanliness score, it may be possible to estimate the possibility of active bleeding. 
Our study had several limitations. First, this study was a retrospective and single-center study. As a result, it is possible that several variables were not controlled. In addition, although bowel preparation education was provided to the patients in a uniform way, the preparation may have been inadequate depending upon the patient. Finally, because the number of inadequate cleansing groups was small, it was difficult to accurately compare the diagnostic yields. Additional large-scale studies are needed to compare diagnostic yields.

In conclusion, our study using validated Al algorithm at the full-length small bowel level identified that there was no significant effect on bowel cleanliness and diagnostic yield even if SBCE was performed immediately after colonoscopy. Small bowel cleanliness was not significantly related to the dose and time of purgative taken prior to SBCE. Also, adequate mucosal visualization was maintained even when same-day and low-dose purgative preparation was used before SBCE. However, if colon preparation is not good, additional preparation before SBCE may be necessary. A further well-designed prospective study is needed.

\section{Methods}

\section{[1] Study population and variables}

We performed a retrospective, single-center study at Dongguk University Ilsan Hospital, Republic of Korea. Patients who underwent SBCE (PillCam SB3, GIVEN Imaging Ltd., Yoqneam, Israel) between January 1 , 2018, and December 31, 2020, were included in the study. Patients who underwent SBCE other than Pillcam SB3, incomplete (unable to identify the cecum) SBCE studies, and those with inaccurate or missed data were excluded.

Eighty-five patients who met the inclusion criteria were finally enrolled in the study. The following variables were analyzed based on electronic medical records and endoscopic images: age, gender, American Society of Anesthesiologists (ASA) classification, whether colonoscopy was performed before SBCE, reasons for SBCE, time from taking the last dose of purgative to colonoscopy and SBCE, whether prokinetics were used, gastric and small bowel transit time. This study was approved by the Institutional Review Board of Dongguk University Ilsan Hospital (DUIH 2021-08-036-001). All methods in this study were carried out in accordance with relevant guidelines and regulations. And, informed consent was obtained from all subjects or, if subjects are under 18 , from a parent and/or legal guardian.

\section{[2] Endoscopy procedure and purgative administration time (Figure 4)}

(1) Small bowel capsule endoscopy alone

Patients undergoing only SBCE were instructed to fast for 12 hours overnight, start taking the purgative 3 hours before the SBCE, and finish taking it 1 hour before the SBCE. All patients were instructed to take a purgative consisting of half dose (total 1 liter with clear liquid) of polyethylen glycol (PEG) $3350+$ ascorbic acid (Coolprep ${ }^{\mathrm{TM}}$, Taejoon Pharm Co., Ltd, Seoul, Korea). 
(2) Small bowel capsule endoscopy after colonoscopy

In this case, SBCE was performed about 1 hour after the end of the colonoscopy. For the colonoscopy, the colon was prepared by full dose (total 2 liter with clear liquid) of Coolprep ${ }^{\mathrm{TM}}$ using either the split-dose or the same-day regimen. In the case of colonoscopies before noon, the patients were instructed to take the first dose at $8 \mathrm{pm}$ the day before and the last dose at 6 am on the day of colonoscopy as in the split-dose regimen. In the case of colonoscopies in the afternoon, the patients were instructed to take the first dose at 6 am and the last dose at 9 am on the day of colonoscopy as in the same-day regimen. The patients were instructed to complete taking the purgative 2 hours before the colonoscopy. Midazolam and pethidine were administered for sedation colonoscopy. If the colonoscopy was completed and the indications for SBCE were applicable, antidotes such as flumazenil and naloxone were administered and the patient was observed for one hour. And then, capsule endoscope was swallowed under the supervision of a medical staff. A prokinetic agent was administered if necessary when slow gastric transit time was expected in relation to sedative administration.

\section{[3] Artificial intelligence (Al) algorithm for calculating bowel cleanliness score}

In this study, a convolutional neural network (CNN) algorithm for calculating bowel cleanliness scores based on InceptionResnetV2 was used. ${ }^{11}$ Each SBCE image was calculated according to a 5-step scoring method. A cleanliness score of 1 was calculated when the mucosal visualization was less than $25 \%$ and a score of 5 when the mucosal visualization was $90 \%$ or more. In the previous study, when the cut-off cleanliness score value was 3.25 , the area under the curve (AUC) of 0.977 for adequate and inadequate bowel preparation was confirmed. Therefore, the same cut-off score (3.25) was applied in this study as well.

Two expert endoscopists (Oh, D.J., Nam, J.H.) identified the images of duodenal and cecal transition in each SBCE case. Afterwards, only small bowel images were extracted and a small bowel cleanliness score was automatically calculated by the Al algorithm that measures the score of each image (Figure 5).

\section{[4] Outcomes and statistical analyses}

The primary outcome was the difference in small bowel cleanliness scores between the SBCE immediate after colonoscopy and SBCE alone. The secondary outcome was to identify the factors related to poor small bowel cleanliness scores. Student's t-test and Chi-square analysis were performed on the variables. Analysis of variance (ANOVA) were performed to analyze the differences among the three or more groups. Factors for poor preparation were analyzed by logistic regression with odds ratios (ORs) and $95 \%$ confidence intervals (Cls). Statistical significance was set at a $p$ value of $<0.05$ in both univariate and multivariate analyses. Statistical analysis was carried out by IBM SPSS Statistics v25.

\section{Declarations}

Data availability statement 
The data that supports the findings of this study are available within the article.

\section{Acknowledgement}

This study was supported by a grant (Grant Number: HI19C0665) from the Korean Health Technology R \& D project through the Korean Health Industry Development Institute (KHIDI) funded by the Ministry of Health \& Welfare, Republic of Korea. We thank our laboratory researchers (Hee Kyoung Song, Sung Kyung Lee) for data anonymization, image extraction, and image separation.

\section{Author contributions}

Oh, D.J. conducting the study, drafting the manuscript; Hwang, Y. interpreting data, conducting the study; Nam, J.H. collecting data, data analysis; Lim, Y.J. design of the work, revising the manuscript, final approval of the version to be published.

\section{Competing Interests Statement}

The authors declare no competing interests.

\section{References}

1. Wang, A., et al. Wireless capsule endoscopy. Gastrointest Endosc. 78, 805-815 (2013)

2. Pennazio, M., et al. Small-bowel capsule endoscopy and device-assisted enteroscopy for diagnosis and treatment of small-bowel disorders: European Society of Gastrointestinal Endoscopy (ESGE) Clinical Guideline. Endoscopy. 47, 352-376 (2015).

3. Enns, R.A., et al. Clinical Practice Guidelines for the Use of Video Capsule Endoscopy. Gastroenterology. 152, 497-514 (2017)

4. Spada, C., et al. Performance measures for small-bowel endoscopy: a European Society of Gastrointestinal Endoscopy (ESGE) Quality Improvement Initiative. Endoscopy. 51, 574-598 (2019).

5. Hassan, C., et al. Bowel preparation for colonoscopy: European Society of Gastrointestinal Endoscopy (ESGE) Guideline - Update 2019. Endoscopy. 51, 775-794 (2019).

6. Saltzman, J.R., et al. Bowel preparation before colonoscopy. Gastrointest Endosc. 81, 781-794 (2015).

7. Rondonotti, E., et al. Small-bowel capsule endoscopy and device-assisted enteroscopy for diagnosis and treatment of small-bowel disorders: European Society of Gastrointestinal Endoscopy (ESGE) Technical Review. Endoscopy. 50, 423-446 (2018).

8. Gurudu, S.R., et al. The role of endoscopy in the management of suspected small-bowel bleeding. Gastrointest Endosc. 85, 22-31 (2017).

9. Singh, A., et al. Timing of video capsule endoscopy relative to overt obscure GI bleeding: implications from a retrospective study. Gastrointest Endosc. 77, 761-766 (2013). 
10. Lee, H.S., et al. Diagnostic Value of Small Bowel Capsule Endoscopy in Isolated Ileitis: A CAPENTRY Study. Dig Dis Sci. 62, 180-187 (2017).

11. Nam, J.H., et al. Development of a deep learning-based software for calculating cleansing score in small bowel capsule endoscopy. Sci Rep. 11, 4417 (2021).

12. Kastenberg, D., Bertiger, G. \& Brogadir S. Bowel preparation quality scales for colonoscopy. World J Gastroenterol. 24, 2833-2843 (2018).

13. Yung, D.E., Plevris, J.N., Leenhardt, R., Dray, X., Koulaouzidis, A. \& ESGE Small Bowel Research Working Group. Poor Quality of Small Bowel Capsule Endoscopy Images Has a Significant Negative Effect in the Diagnosis of Small Bowel Malignancy. Clin Exp Gastroenterol. 13, 475-484 (2020).

14. Dray, X., et al. Prospective evaluation of third-generation small bowel capsule endoscopy videos by independent readers demonstrates poor reproducibility of cleanliness classifications. Clin Res Hepatol Gastroenterol. 45, 101612 (2021).

15. Noorda, R., Nevarez, A., Colomer, A., Beltran, V.P. \& Naranjo, V. Automatic evaluation of degree of cleanliness in capsule endoscopy based on a novel CNN architecture. Sci Rep. 10, 17706 (2020).

16. Leenhardt, R., et al. A neural network-based algorithm for assessing the cleanliness of small bowel during capsule endoscopy. Endoscopy. 53, 932-936 (2021).

17. Nam, J.H., et al. Development and Verification of a Deep Learning Algorithm to Evaluate Small-Bowel Preparation Quality. Diagnostics (Basel). 11, 1127 (2021).

18. Squirell, E., Ricci, M. \& Hookey, L. Preparation, Timing, Prokinetics, and Surface Agents in Video Capsule Endoscopy. Gastrointest Endosc Clin N Am. 31, 251-265 (2021).

19. Gkolfakis, P., Tziatzios, G., Dimitriadis, G.D. \& Triantafyllou, K. Meta-analysis of randomized controlled trials challenging the usefulness of purgative preparation before small-bowel video capsule endoscopy. Endoscopy. 50, 671-683 (2018).

20. Bahar, R., Gupta, A. \& Mann, S.K. Clear Liquids versus Polyethylene Glycol Preparation for Video Capsule Endoscopy of the Small Bowel: A Randomized Controlled Trial. Digestion. 99, 213-218 (2019).

21. Hookey, L., et al. Lack of benefit of active preparation compared with a clear fluid-only diet in smallbowel visualization for video capsule endoscopy: results of a randomized, blinded, controlled trial. Gastrointest Endosc. 85, 187-193 (2017).

22. Wu, S., et al. Low-dose and same day use of polyethylene glycol improves image of video capsule endoscopy: A multi-center randomized clinical trial. J Gastroenterol Hepatol. 35, 634-640 (2020).

23. Kim, S.H., et al. Changes in performance of small bowel capsule endoscopy based on nationwide data from a Korean Capsule Endoscopy Registry. Korean J Intern Med. 35, 889-896 (2020).

24. Kotwal, V.S., Attar, B.M., Gupta, S. \& Agarwal, R. Should bowel preparation, antifoaming agents, or prokinetics be used before video capsule endoscopy? A systematic review and meta-analysis. Eur J Gastroenterol Hepatol. 26, 137-145 (2014). 


\section{Tables}

Table 1. Baseline characteristics of patients who underwent small bowel capsule endoscopy (SBCE) (N = 85)

\begin{tabular}{|c|c|c|c|}
\hline Variables & $\begin{array}{l}\text { SBCE after colonoscopy } \\
\qquad(\mathrm{n}=50)\end{array}$ & $\begin{array}{l}\text { SBCE alone } \\
(n=35)\end{array}$ & $\mathrm{P}$ \\
\hline Mean age, years & $49.1 \pm 19.8$ & $49.0 \pm 23.0$ & 0.981 \\
\hline$>65$ years old & $10(20.0 \%)$ & $9(25.7 \%)$ & 0.534 \\
\hline Male gender & $35(70.0 \%)$ & $17(48.6 \%)$ & 0.046 \\
\hline ASA & & & 0.463 \\
\hline $\mathbb{Q} \mathrm{\square}$ & $43(86.0 \%)$ & $28(80.0 \%)$ & \\
\hline$\nabla-\square$ & $7(14.0 \%)$ & $7(20.0 \%)$ & \\
\hline Reasons for SBCE & & & 0.838 \\
\hline (suspected) small bowel bleeding & $23(46.0 \%)$ & $15(42.9 \%)$ & \\
\hline (suspected) Crohn's disease & $22(44.0 \%)$ & $17(48.6 \%)$ & \\
\hline (suspected) tumor or polyposis & $4(8.0 \%)$ & $3(8.5 \%)$ & \\
\hline (suspected) drug induced enteropathy & $1(2.0 \%)$ & $0(0.0 \%)$ & \\
\hline \multicolumn{4}{|l|}{ Diagnostic yield } \\
\hline small bowel bleeding & $43.5 \%(10 / 23)$ & $53.3 \%(8 / 15)$ & 0.552 \\
\hline Crohn's disease & $63.6 \%(14 / 22)$ & $64.7 \%(11 / 17)$ & 0.945 \\
\hline tumor or polyposis & $50 \%(2 / 4)$ & $33.0 \%(1 / 3)$ & 0.659 \\
\hline drug induced enteropathy & $100 \%(1 / 1)$ & & N/A \\
\hline Taking prokinetics after SBCE & $32(64.0 \%)$ & $10(28.6 \%)$ & 0.001 \\
\hline Mean small bowel transit time, hours & $5.85 \pm 2.08$ & $5.36 \pm 2.69$ & 0.353 \\
\hline Mean gastric transit time, hours & $1.32 \pm 1.18$ & $0.84 \pm 1.10$ & 0.059 \\
\hline Mean time from purgative* to $S B C E$, hours & $6.86 \pm 0.94$ & $3.00 \pm 0.18$ & 0.000 \\
\hline
\end{tabular}

ASA, American Society of Anesthesiologists; SD, standard deviation

*Last dose of purgative 
Table 2. Analysis of artificial intelligence algorithm calculated full length small bowel capsule endoscopy $(\mathrm{N}=85)$

\begin{tabular}{|llll|}
\hline Variables & $\begin{array}{c}\text { SBCE after colonoscopy } \\
(\mathrm{n}=50)\end{array}$ & $\begin{array}{l}\text { SBCE alone } \\
(\mathrm{n}=35)\end{array}$ & $\mathrm{P}$ \\
\hline Mean number of images in SBCE (SD) & $12976.6 \pm 7240.3$ & $10771.9 \pm 5389.3$ & 0.130 \\
Al calculated Cleanliness score (SD) & $3.970 \pm 0.603$ & $3.937 \pm 0.428$ & 0.785 \\
Cases of adequate cleansing & $43(86.0 \%)$ & $32(91.4 \%)$ & 0.445 \\
\hline Cases of good cleansing & $27(54.0 \%)$ & $17(48.6 \%)$ & 0.622 \\
\hline
\end{tabular}

SBCE, small bowel capsule endoscopy; Al, artificial intelligence; SD, standard deviation

Table 3. Univariate and multivariate analysis of adequate cleansing cases $(\mathrm{N}=85)$ 


\begin{tabular}{|c|c|c|c|c|}
\hline \multirow[t]{2}{*}{ Variables } & \multicolumn{2}{|c|}{ Cleanliness score } & \multirow{2}{*}{$\begin{array}{l}\text { Univariate, } \\
\mathrm{P}\end{array}$} & \multirow{2}{*}{$\begin{array}{l}\text { Multivariate } \\
\mathrm{P}(\mathrm{OR} ; 95 \% \\
\mathrm{Cl})\end{array}$} \\
\hline & $\begin{array}{l}\text { Adequate } \\
(\mathrm{n}=75)\end{array}$ & $\begin{array}{l}\text { Inadequate } \\
(\mathrm{n}=10)\end{array}$ & & \\
\hline Age > 65years & $\begin{array}{l}17 \\
(22.7 \%)\end{array}$ & $2(20.0 \%)$ & 0.849 & \\
\hline Male gender (\%) & $\begin{array}{l}43 \\
(57.3 \%)\end{array}$ & $9(90.0 \%)$ & 0.046 & $\begin{array}{l}0.096 \\
(6.33 ; 0.72- \\
55.46)\end{array}$ \\
\hline ASA class I or II (\%) & $\begin{array}{l}63 \\
(84.0 \%)\end{array}$ & $8(80.0 \%)$ & \multirow[t]{2}{*}{0.749} & \\
\hline ASA class $\geq$ III (\%) & $\begin{array}{l}12 \\
(16.0 \%)\end{array}$ & $2(20.0 \%)$ & & \\
\hline \multicolumn{3}{|l|}{ Lesions identified in SBCE } & \multirow[t]{5}{*}{0.592} & \\
\hline & $\begin{array}{l}11 \\
(14.7 \%)\end{array}$ & & & \\
\hline ulcers/erosions & & $4(40.0 \%)$ & & \\
\hline polyps & $(46.7 \%)$ & $0(0.0 \%)$ & & \\
\hline no definite lesion & $4(5.3 \%)$ & $3(30.0 \%)$ & & \\
\hline \multirow{6}{*}{$\begin{array}{l}\text { Diagnostic yield } \\
\text { small bowel bleeding } \\
\text { Crohn's disease } \\
\text { tumor or polyposis } \\
\text { drug induced enteropathy }\end{array}$} & \multirow{2}{*}{$\begin{array}{l}25 \\
(33.3 \%)\end{array}$} & & & \\
\hline & & $80.0 \%$ & 0.117 & \\
\hline & \multirow{3}{*}{$\begin{array}{l}42.4 \% \\
65.7 \% \\
50.0 \%\end{array}$} & $50.0 \%$ & \multirow{4}{*}{$\begin{array}{l}0.535 \\
0.350 \\
\text { N/A }\end{array}$} & \\
\hline & & \multirow[t]{3}{*}{$0.0 \%(0 / 1)$} & & \\
\hline & & & & \\
\hline & $100 \%$ & & & \\
\hline Pre-colonoscopy (all sedation) & $\begin{array}{l}43 \\
(57.3 \%)\end{array}$ & $7(70.0 \%)$ & 0.445 & $\begin{array}{l}0.729 \\
(1.38 ; 0.22- \\
8.68)\end{array}$ \\
\hline Prokinetics & $\begin{array}{l}37 \\
(49.3 \%)\end{array}$ & $5(50.0 \%)$ & 0.968 & \\
\hline \multirow{2}{*}{$\begin{array}{l}\text { Mean time from purgative }{ }^{\star} \text { to SBCE } \\
\text { prolonged time to SBCE ( }>7 \text { hours) }\end{array}$} & $\begin{array}{l}313.8 \pm \\
123.7\end{array}$ & $\begin{array}{l}335.4 \pm \\
118.1\end{array}$ & \multirow[t]{2}{*}{0.604} & \\
\hline & $\begin{array}{l}20 \\
(26.7 \%)\end{array}$ & $4(40.0 \%)$ & & $\begin{array}{l}0.530 \\
(0.58 ; 0.11- \\
3.17)\end{array}$ \\
\hline \multirow{2}{*}{$\begin{array}{l}\text { Mean small bowel transit time, min Mean } \\
\text { gastric transit time, min } \\
\text { delayed gastric transit (>90 mins) }\end{array}$} & \multirow{2}{*}{$\begin{array}{l}340.3 \pm \\
143.3\end{array}$} & \multirow{2}{*}{$\begin{array}{l}327.8 \pm \\
126.6\end{array}$} & 0.795 & \\
\hline & & & 0.045 & \\
\hline
\end{tabular}




$\begin{array}{llll}61.6 \pm & 108.6 \pm & 0.048 & 0.107 \\ 64.1 & 97.8 & & (0.30 ; 0.07- \\ 16 & 5(50.0 \%) & & 1.29) \\ (21.3 \%) & & \end{array}$

ASA, American Society of Anesthesiologists; SD, standard deviation

*Last dose of purgative

\section{Figures}

Small Bowel

Cleanliness Score

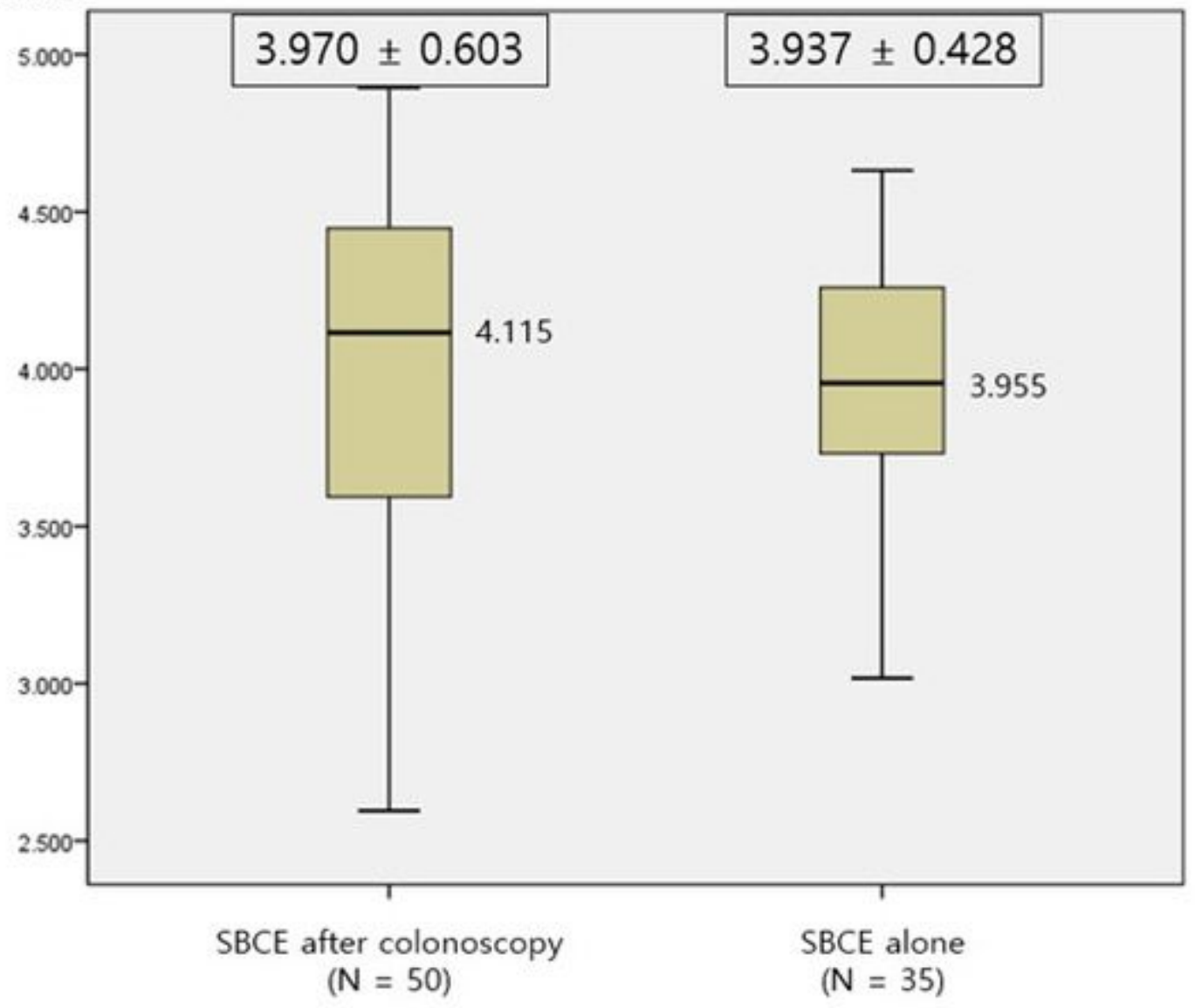

Figure 1

Relationship between small bowel cleanliness score and pre-colonoscopy. The mean small bowel cleanliness score in small bowel capsule endoscopy (SBCE) immediately after colonoscopy was $3.970 \pm$ 0.603 , and in SBCE alone was $3.937 \pm 0.428$. There was no significant difference between the colonoscopy and small bowel cleanliness score $(p=0.785)$. 


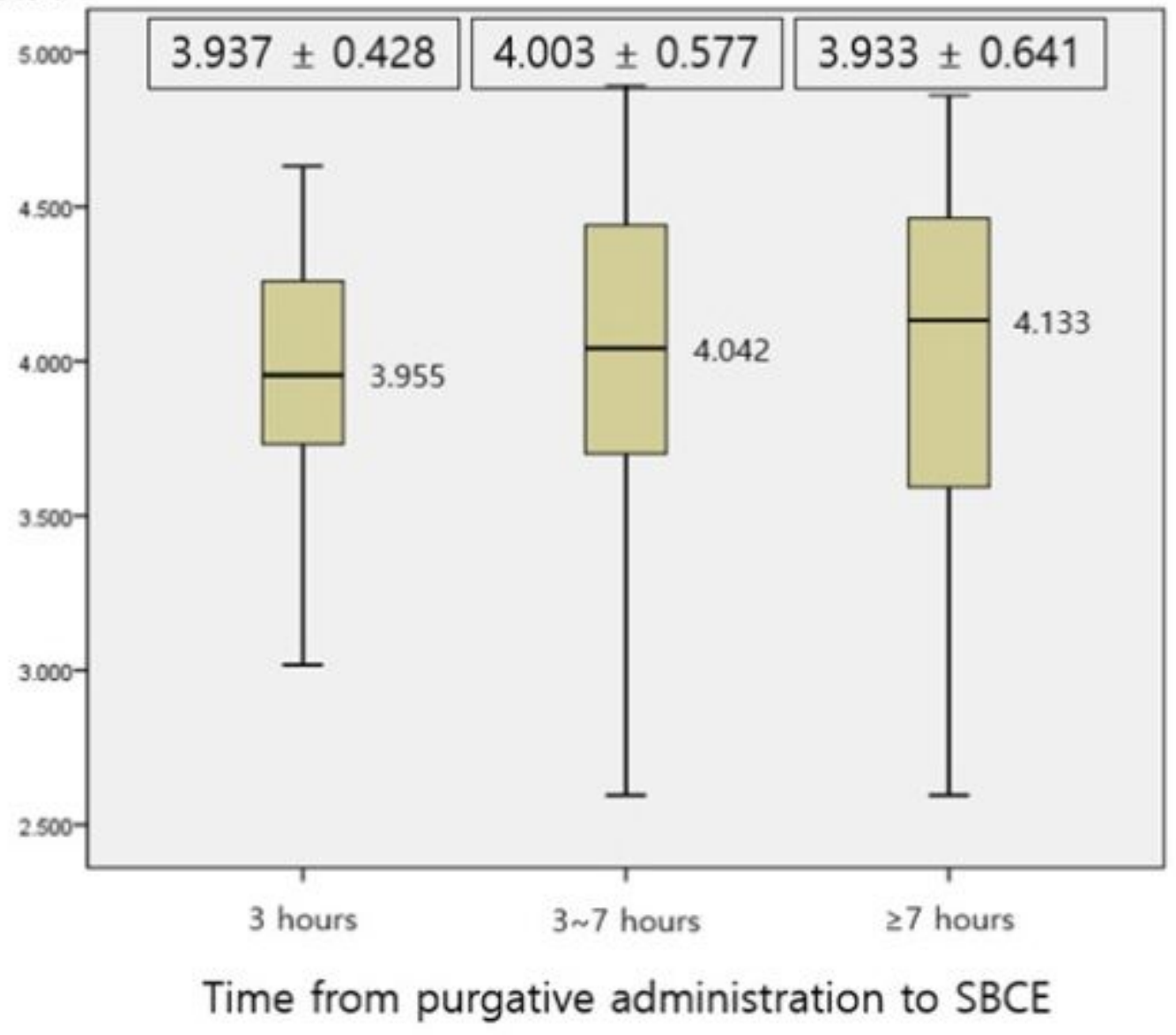

Figure 2

Relationship between small bowel cleanliness score and time from the last dose of purgative administration to small bowel capsule endoscopy (SBCE). The time from the last dose of purgative administration to SBCE was divided into 3 hours and 7 hours intervals. There was no significant difference between the three groups $(p=0.831)$. 


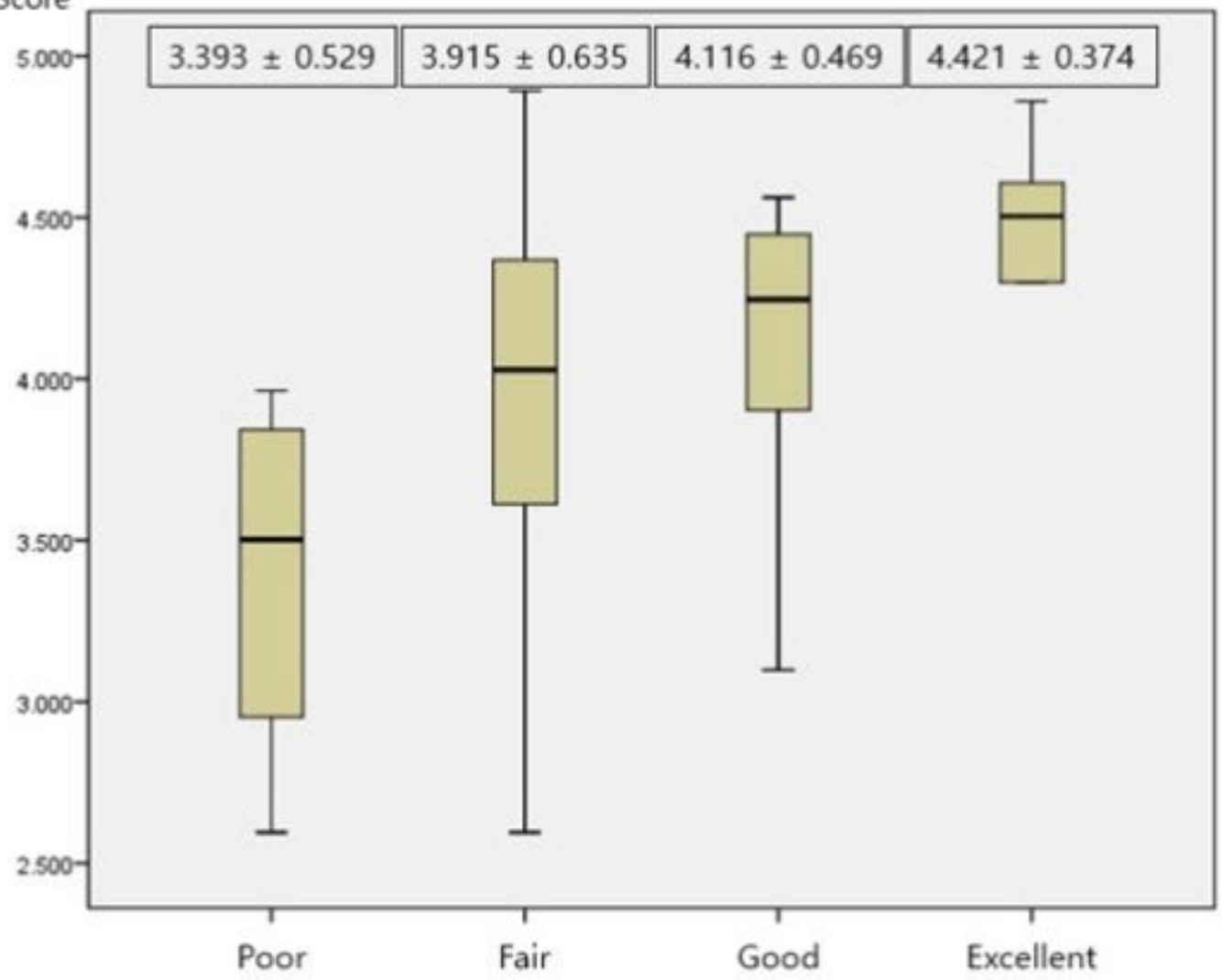

Colon preparation scale in colonoscopy

\section{Figure 3}

Colon preparation scale in colonoscopy and small bowel cleanliness scores. The colon preparation scale was measured by Aronchick Scale (from inadequate to excellent). The colon preparation was better, the small bowel cleanliness score was higher $(p=0.015)$.

\section{Figure 4}

Schematic of the study process. (A) In the case of performing a small bowel capsule endoscopy (SBCE) immediately after colonoscopy, bowel preparation was performed by the split-dose or same-day regimen using 2 liters of polyethylen glycol (PEG) + ascorbic acid. After colonoscopy, SBCE was performed about an hour later if necessary. (B) The bowel preparation for SBCE was performed by same-day and low dose preparation. Patients undergoing SBCE were instructed to start taking the 1 liter of purgative 3 hours before the SBCE, and finish taking it 1 hour before the SBCE. 
A

Calculated cleanliness score by $\mathrm{Al}$ algorithm

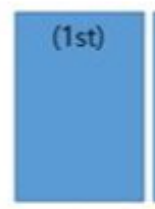

5

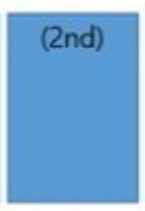

4

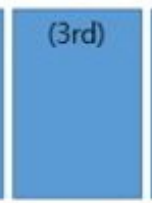

4

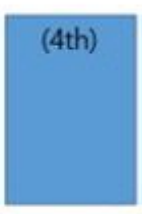

5

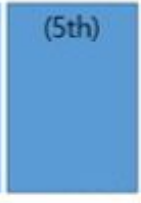

3

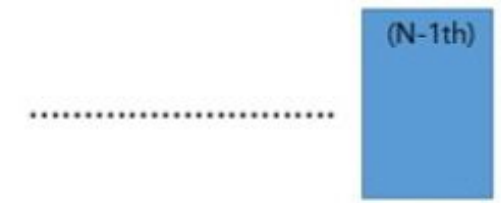

2

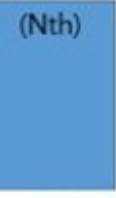

3

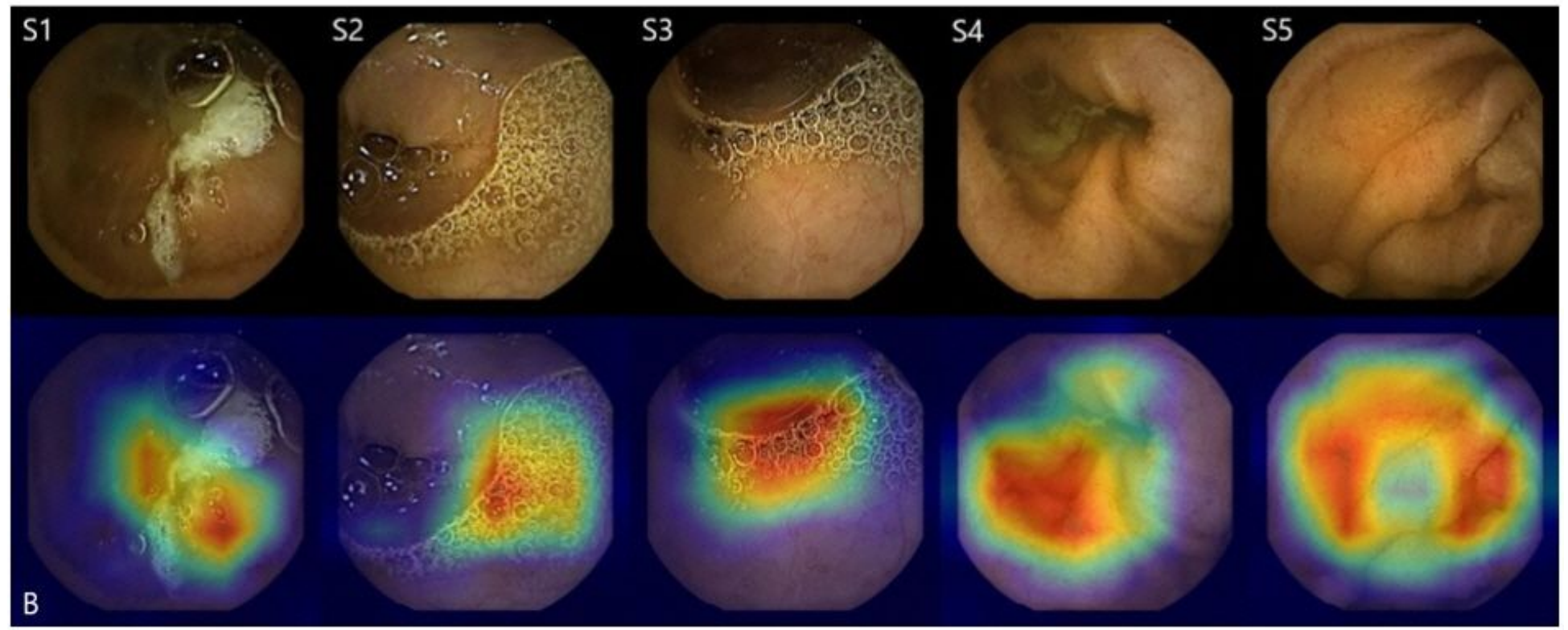

\section{Figure 5}

Real example of small bowel cleanliness score calculated by the artificial intelligence (Al) algorithm in a small bowel capsule endoscopy case (Case No.60). (A) The small bowel cleanliness was scored from 1.0 (S1) to 5.0 (S5). (B) The image analysis by Al algorithm was expressed in a Grad-CAM visualization (heatmap). 